\title{
Investigation of Sustainable Housing Criteria
}

\author{
Somayeh roshanfekr ${ }^{1, a}$, N.M.Tawil ${ }^{2}$ and N.A.Goh ${ }^{1}$ \\ ${ }^{1}$ Department of architecture, faculty engineering and built environment, national university of Malaysia \\ ${ }^{2}$ Department of architecture, faculty engineering and built environment, national university of Malaysia
}

\begin{abstract}
Recently, much attention has been paid to sustainable development in cities. The quality of human life is directly related to environmental quality. Because many people live in cities as a place of social, economic and cultural relationships, certain issues such as environmental crises, energy, air and noise pollution and traffic jams are some of the factors that can alter the quality of human life. Therefore, in order to improve the quality of human life, attention to sustainable development (or sustainability) in cities is proposed. Sustainable building has a comprehensive significance that begins with the conception of negative and positive impacts on the environment. Several descriptions of sustainable or green buildings have been created; however, they all pursue one goal, which is to create sustainable urban developments and protection of the environment. The quality of indoor environments, materials, and energy consumption, water usage, the impact of building construction processes and building maintenance are some of the factors that affect the environment and sustainability. Sustainable building is an attempt to relieve the minus impacts on the environment that occur during a building's lifetime. This research investigates the important factors that have relevance to green buildings and introduces several criteria of sustainable housing.
\end{abstract}

Keywords: sustainable housing, green building, criteria of sustainable housing.

\section{Introduction}

According to the UN Commission on Human Settlements, sustainable development of human settlement makes sure social and economic progress, as well as adequate job prospects are in robust synchronization with the environs. The definition encompasses the main values of the Rio Declaration on Environment and Development as well as of the UN Conference on Environment and Development: anticipatory approach, avoidance of contamination, high regard for the carrying ability of the ecosystem and conservation of prospects for the coming generations [11]. For instance, according to Daly [6], one needs to understand the difference between development, which is essentially a qualitative enhancement, and growth, which is a positive change in volume or magnitude (for example, populace and resource). Growth can, however, only be finite, as we have inhabited only one planet. A suite of natural systems that offer many ecosystem services surrounds housing. It is vital to comprehend the relationship between natural systems and housing and consider it when designing and constructing accommodations and colonies [11]. The building industry's behavior is extremely important as far as environmental viability is concerned [5]. Sustainable housing presents multiple prospects of promoting economic growth, ecological stewardship, standard of living, and social parity

\footnotetext{
${ }^{\mathrm{a}}$ Corresponding author: so.roshanfekr@gmail.com
}

while alleviating the unwarrantable convergences of issues pertaining to urbanization, population growth, poverty, slums, economic volatility, climate change, and inadequate access to sustainable energy [1]. The term 'sustainable building' pertains more specifically to the objective of designing and constructing structures which have no clear unfavorable effects on the environs, so that an entire built environment comprising similar structures can co-exist in the environmental balance for an indefinite period [14]. From Global Green USA [8]'s point of view, sustainable buildings offer multiple direct and indirect advantages across all geographical levels, i.e. individual, communal, regional, and global. As far as the global level is concerned, green buildings aid in safeguarding and preserving natural resources by decreasing the demand for usage of virgin materials. This survey aims to investigate the criteria for sustainable housing. This paper developed introductory information of sustainable housing According to individual knowledge along with literature review of evaluating and comprehension of sustainable housing criteria.

\section{Sustainable Housing Criteria}

Creating a sustainable building is a process that builds houses, buildings and auxiliary infrastructures while 
reducing resource consumption, decreasing detrimental environmental impacts, and offering healthier living environments [27].

Ideally, housing development should be not only viable and of excellent quality but also:

A. Inexpensive

The housing and accommodation should have been constructed, administered, and upheld at a judicious cost, and the form of the development taken into consideration.

B. Socially and Ecologically Suitable

The type of housing, support services, and facilities offered should address the requirements of those who are to be housed. The type, size, and terms of accommodation should aid comprehensive ecological, social, and economic sustainability policy goals for the region and endorse the development of properly assimilated recreation and amusement spaces.

C. Accessible and Flexible

Not all citizens, including those with impaired movement, should face any obstacles in access and motion. They should be able to travel liberally within and across the development, access buildings, and capitalize on the facilities and services offered. Houses should be adaptable enough to cater to the varying needs of citizens during the course of their lifespan.

D. Resource Efficient

Infrastructure, land, and energy should be utilized effectually. The place should be well-located in terms of conveyance, services, and facilities. Design, as well as house position, should consider the site topography in order to manage negative wind impacts and maximize the advantages of daylight, sunlight, and solar paybacks. Renewable energy sources should be utilized optimally. Scarce natural resources should be consumed in moderation during the building, upkeep, and administration of the houses.

E. Safe, Secure, and Healthy

The housing should be a safe and healthy place to stay in. Cyclists and pedestrians should find it easy and safe to travel within and across the locality. Vehicular movement, including entry and exit for service vehicles, should not hamper these goals.

F. Long-lasting

The finest construction methods should be deployed and the main aspects of construction should have a service lifespan of around sixty years without the requirement for uncharacteristic repairs or replacements.

G. Architecturally Proper

The accommodation should offer a pleasing environment that is appealing as well as appropriate. The design should be such that it should comprehend and respond aptly to its context, enhance the vicinity, and have a high regard for its cultural legacy [4]. Some have ratiocinate which a framework is helpful rather than a special description because of incomplete definitions of sustainability [16,17,2]. This framework have constructed to aid specify housing for sustainable development perspective. Figure 1 showed sustainable housing criteria.

Utmost of the sustainable housing literature review concentrate on environmental situation $[9,12,1317,18,20,21,22,28]$. Housing is a basic social setting, which establishes the standard of living and well- being of individuals and places. The places where accommodations are located, the way they are designed and constructed, and the manner in which they interlace with the socio-cultural, environmental, and economic structures of communities are aspects which impact the day-to-day lives of individuals, their health, safety, and welfare, and which, considering the lengthy life span of houses as physical structures, impact the

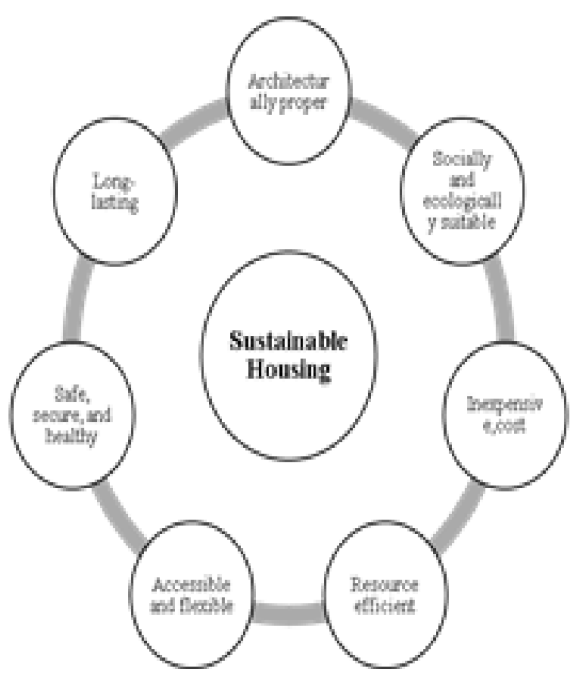

Figure 1: sustainable housing criteria

present as well as coming generations. Thus, housing is the core of sustainable development [1]. It is crucial that standards of sustainable design are abided by, and proper technologies are deployed in sustainable housing rollouts. Sustainable design standards in sustainable housing should also encompass the following: sustainable construction materials, thermally effectual design, renewable energy alternatives, energy efficacy, waste reduction and recycling and viable water and sanitation systems [11]. Figure 2 showed a sustainable housing in Australia.

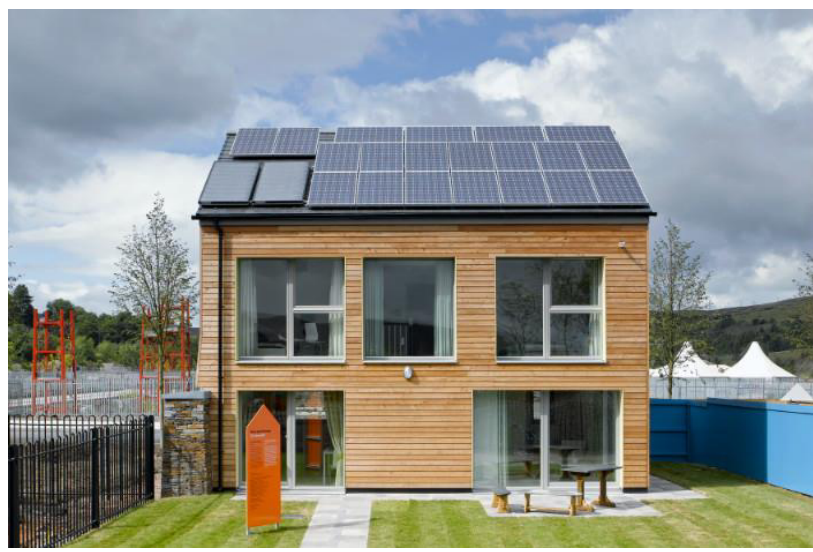

Figure 2: sustainable housing, Suzanne Toumbourou 2015

To create sustainable housing, it is crucial to utilise native and untreated construction materials. This reduces transport 
and energy requirements as well as air contamination, besides generating local job prospects. In addition, greater localization ensures greater retention of money within the community [11]. On the whole, buildings and related materials manufactured for construction purposes are responsible for at least $30 \%$ of greenhouse gas discharges around the world [23]. On the other hand, recycled construction material is important in sustainable housing. Recycling is a vital element of green structures. It decreases non-renewable involvements, particularly usage of energy, mining activities, and cost of transportation. This encompasses the usage of waste products and used construction material. It is particularly crucial to reuse ecologically hostile materials that trickle contaminated materials into the earth and groundwater, or discharge methane into the environment when deposited in landfills [11]. The idea of sustainable energy involves the creation and effectual utilization of energy in a manner that enables us to cater to current needs without conceding the capability of upcoming generations to satisfy their own wants and requirements. Optimizing the viability of social accommodation by means of enhanced thermal performance and insulation criterions, thus decreasing greenhouse gas emissions owing to lower energy needs, would help achieve Ireland's obligations under the Kyoto Protocol [4]. Initiatives regarding sustainable buildings have conventionally emphasized bettering building performance and, at the same time, alleviating the negative ecological effects of the built environment. This is achieved through actions to reduce utilization of water and energy, decrease greenhouse gas discharges, and lower the quantity of solid waste and building debris that is dumped in landfills. Such programs characteristically stipulate eco-friendly materials and focus on the design and development of a venture, its consequent operations, and continuing upkeep. The advantages of sustainable structures with respect to energy efficacy and ecological impacts have been substantiated [3] Moreover, the United States Green Building Council [26] has stated that sustainable buildings can aid in safeguarding and conserving open spaces, decreasing solid waste, improving transport options, lowering pressure on local infrastructure, better managing storm-water, improving quality of water, decreasing water contamination, and improving community welfare through growth-oriented planning. Of late, there have been increasing instances of health concerns attributed to building design and development, and the materials utilized in the building process. Lead-based paints trigger extreme developmental issues and damage to the brain, particularly in children. Asbestos is a heat-resistant fiber utilized in house building materials right from the roofing to the flooring. It is extremely carcinogenic in nature. Just like the inadvertent concerns generated by tenement architecture, initial efforts to enhance building performance might have led to "sick" structures, wherein high amounts of indoor air contaminants were noted [3]. Furthermore, sustainable housing takes into consideration the quality of indoor air provided to inhabitants, considering around 1.3 million perish prematurely every year owing to exposure to indoor air contamination from combustion of biomass [24]. Development of accommodation presents several ecological challenges. It is imperative to determine accommodation solutions that do not severely affect housing affordability and improve urban standard of livings. Furthermore, it is necessary to determine viable accommodation solutions that tackle the increasing carbon footprint of the built environs, and that do not expose more homes to levels of carbon emissions, which are unmanageable with respect to operational and exemplified carbon loads (much like the present scenario with most housing performance in affluent nations). If such substandard performance were replicated at the global level, it would aggravate ecological change. Sustainable housing has the ability to directly or indirectly handle prevailing issues in urban areas, including management of storm water and solid waste, water supply, hygiene, and pest control [25].

Cognizance and knowledge of the different concerns involved, local perspective, and alternatives available are necessary to make proper green and sustainable decisions. The following are the likely monetary, ecological, and social advantages of greater resource efficacy savings in sustainable housing:

Lessen exhaustion of natural resources during the building (lower waste from materials) and operation (no or minimal use of fossil fuels) stages by utilising effectual construction materials and methods as well as renewable energy sources.

Lower cost of operations of households in the form of lower utility bills, resulting in lower paucity in terms of water and fuel.

Comfortable and sanitized conditions to promote better health of the inhabitants.

Utilisation of effectual water and waste management practices.

Lower macro-infrastructure demands, such as electricity.

Lower cost of transportation (with regards to sustainable urban setting).

Long-term ecological benefits from lower pollution and usage of resources.

Advantages of using native natural construction material: reduced transportation needs, reduced embodied energy, easy upkeep, and possibility of reuse and recyclability. Use of native materials that can be effortlessly replaced or repaired and lower utilisation of water and energy certainly leads to decreased life-cycle costs of accommodations [15]. A structure's environmental performance can be enhanced by opting for ecologically preferable construction material. In reality, ecological performance should be weighed against economic performance. All construction material manufacturers and environment-conscious building designers seek to weigh ecological advantages against economic costs. They endeavor to determine construction material, which enhances environmental performance without impacting on the cost factor. Furthermore, housing is a component of the society-environment relationship. Construction of houses and their operation utilizes huge volumes of natural resources such as energy, land, water, and building materials. It also generates waste, and triggers water and air contamination. That said, housing faces different negative environmental effects and threats, such as those related to climate change and natural calamities. These factors need to be considered in the process of sustainable development.() 
When it comes to community and regional levels, greenbuilt accommodations can aid in boosting local economic growth by promoting usage of local and regional supplies, thus retaining the money within the local community itself [7].

\section{Conclusion}

The aim of sustainable housing is to ensure the minimal negative effect of buildings and their operations on human wellbeing and conditions as well as the environs by means of better design, positioning, construction, functioning, upkeep, and the entire life cycle of the building. Largely, all sustainable structures are conceived to be energy- and resource-efficient, to utilize the appropriate materials (i.e. being recycled, economical, and robust) and to lower the discharge of lethal substances during their life span. Furthermore, a sustainable structure can diminish the unwanted human effects on the buildings assets and materials as well as natural environs and improve human wellbeing and the environment [10]. Safety, energy efficiency, comfort, and material and water efficiency are some factors of sustainable housing. Affordability and social and environmental suitability are other criteria for sustainable housing which help to aid sustainable housing development.

\section{References}

1. UN-Habitat, United Nations Human Settlements Programme. "Sustainable Housing for Sustainable Cities ." a policy framework for developing countries. (2012)

2. A.T, David and Ken G. "A Framework to guide sustainable housing development ." J. o. t. Hus. Edu. and Rch .As. (2010)

3. B, Noreen. "Green Housing = Improved Health:A Winning Combination ." National Center for Healthy Housing (2011).

4. Department of the Environment . "Quality Housing for Sustainable Communities Best Practice Guidelines for Quality Housing for Sustainable Communities , ." DELIVERING HOMES SUSTAINING COMMUNITIES Department of the Environment, Heritage and Local Governme (2007).

5. E, Piet, Nils K and John M.Q. "Program On Housing And Urban Policy Working Paper Series, working paper no. W08-001 doing well by doing good? ." green office buildings, University Of California, Berkeley. (2008).

6. E.H, Daly. " Beyond Growth: The Economics of Sustainable Development." Boston: Beacon Press. (1996).

7. Federal Home Loan Bank of Atlanta. The little green book. Atlanta, Georgia : Federal Home Loan Bank of Atlanta, (2005).

8. Global Green USA. "Greening affordable housing: Trends and opportunities." Presentation at USGBC Greenbuild Conference, November 7(2005).
9. H, Lovell. "Framing sustainable housing as a solution to climate change." J. Env.Policy \& Pln. 6(1), 35-55 (2004).

10. H, Okhovat., Amirkhani. A and Pourjafar. M.R. "Investigating the psychological effects of sustainable buildings on human life." J. Sus. Deve. Vol. 2 (2009): pg. 57-63.

11. H, Paul. and Lisa. TH. "SUSTAINABLE HOUSING, the Sustainability Institute Sustainable Neighbourhood Design Manual: A Non-Technical Guide. Final Draft for Comment."(2009).

12. J, Swanson. "Sustainability sweeps into Broome: Public housing looks set for a makeover in this WA town." Habitat Australia 31(3), 23 (2003).

13. K, Parrott and Emmel J. M. "Sustainability in housing: A curriculum case study." J.f F. and Con.Sci. 93(5), 31-34 (2001).

14. L, alex and joseph L. "Towards Sustainability: Green Building, Sustainability Objectives, and Building America Whole House Systems Research, - 0801." Building America Report (2008).

15. L, Christophe. "Green building interventions for social housing, ." United Nations Human Settlements Programme (UN-Habitat) and United Nations Environment Programme (UNEP) (2015.

16. M, Bhatti. "Greening housing: A challenge for public policy?" Hume Paper on Public Policy 8(4), 63-71 (2000).

17. M, Bhatti, Brooke J and Gibson M. "Housing and the environment: New agenda." The Chartered Institute of Housing (1994).

18. M, Sunikka and Boon C. "Environmental policies and efforts in social housing: The Netherlands." Building Research and Information 31(1), 1-12 (2003).

19. O, Annette. SUSTAI ABLE BUILDI G TECH ICAL MAnUAL Green Building Design, Construction, and Operations . US: Public Technology Inc. n US Green Building Council, (1996).

20. P, Hugo. "How to make housing sustainable? The Dutch experience., ." Env. Pln. B: Planning \& Design 32(1), 5-15 (2005).

21. R. L. H, Chiu . "Social sustainability, sustainable development, and housing development: The experience of Hong Kong. In R. Forrest and J. Lee (Eds.)." Hou. and soc.ch. (2003a): (pp. 211-238).

22. R.L.H, Chiu. "Environmental sustainability of Hong Kong's housing system and the housing process model." Int. Pln. Stu. 5(1), 45-64.5(1), 45-64 (2000).

23. RICS. "Royal Institute of Chartered Surveyors ." Green Value, London and Vancouver (2005).

24. UNEP SBCI. Buildings and climate change. Summary for decision-makers. Paris: UNEP DTIE, (2009a).

25. UN-Habitat and UNEP. The sustainable cities programme in Zambia (1994-2007): Addressing challenges of rapid urbanization. Kenya: UN-Habitat and UNEP, (2009).

26. United States Green Building Council. Rating system for pilot demonstration of LEED ${ }^{\circledR}$ for Homes program, version 1.72. Washington, D.C.: United States: Green Building Council, (2005a). 
27. w, Karlenzig. A blueprint for greening affordable housing: Developer guidelines and resource efficiency and sustainable communities. Santa Monica, California: Global Green USA, (2005).

28. Y, Zhu and Lin B. "Sustainable housing and urban construction in China." Energy \& Buildings 36(12), 1287-1297 (2004). 